\title{
Fatigue Damage Mechanism of AL6XN Austenitic Stainless Steel at High Temperatures
}

\author{
Yanyan Hong ${ }^{1,2} \cdot$ Penglin Gao ${ }^{1} \cdot$ Hongjia $\mathrm{Li}^{1} \cdot$ Changsheng Zhang ${ }^{1} \cdot$ Guangai Sun ${ }^{1}$ \\ Received: 12 September 2019 / Revised: 5 December 2019 / Published online: 18 March 2020 \\ (c) The Chinese Society for Metals (CSM) and Springer-Verlag GmbH Germany, part of Springer Nature 2020
}

\begin{abstract}
By the combination of transmission electron microscope, neutron diffraction and small-angle neutron scattering methods, mechanical fatigue behavior of AL6XN austenitic stainless steel was investigated in the temperature range of $400-600{ }^{\circ} \mathrm{C}$. At $400{ }^{\circ} \mathrm{C}$, in addition to the occurrence of dynamic strain aging, the formation of short-range order was evidenced from the forbidden electron diffraction spot of $1 / 3\{422\}$ in face-centered cubic (fcc) structure viewed down [111] zone axis, which facilitate the planar slip mode of dislocation and result in the work hardening during the fatigue deformation. The fatigue damage is mainly dominated by the accumulation of planar slip band and the interaction among various slip systems. With increasing temperature, precipitates of chi phase, Laves phase and sigma phase were formed during the fatigue tests at 500 and $600{ }^{\circ} \mathrm{C}$. An increase in precipitation content at $600{ }^{\circ} \mathrm{C}$ has also been confirmed by both scanning electron microscope and small-angle neutron scattering analysis. The dislocation pileup originating from the uncoordinated deformation between precipitate and austenitic matrix is an important fatigue damage leading to crack. The continuous cycle softening behavior was also observed on the fatigue curve at $600{ }^{\circ} \mathrm{C}$, which is considered to be caused by dynamic recovery.
\end{abstract}

Keywords Precipitates $\cdot$ Low-cycle fatigue $\cdot$ Austenitic stainless steel $\cdot$ Small-angle neutron scattering $\cdot$ Planar slip bands

\section{Introduction}

The supercritical-water cooled reactor (SCWR) is the only light-water cooled reactor used in the Generation IV nuclear energy system. The significant improvement in safety and economy has made it become a high priority in the nuclear development, and relative research has been carried out actively $[1,2]$. Due to harsh operating conditions, the structural materials in the reactor core must have high strength and low stress corrosion cracking (SCC) sensitivity at elevated temperatures. As one of the candidate materials for SCWR, AL6XN austenitic stainless steel (ASS) has attracted much attention in recent years [3-7]. AL6XN is a

Available online at http://link.springer.com/journal/40195.

Guangai Sun

guangaisun_80@163.com

1 Key Laboratory of Neutron Physics, Institute of Nuclear Physics and Chemistry, CAEP, Mianyang 621900, China

2 Key Laboratory for Anisotropy and Texture of Materials, School of Materials Science and Engineering, Northeastern University, Shenyang 110004, China low carbon, high purity, and nitrogen-bearing "super-austenitic" stainless alloy. Compared with other stainless steels, AL6XN exhibits more excellent corrosion and stress-corrosion resistance at elevated temperatures [3, 4]. In addition, many researchers also documented that the AL6XN alloy not only possesses high strength, but also exhibits good ductility and formability [5-7]. Although advances have been made in understanding the mechanical properties of AL6XN ASS, the deformation mechanism under complex conditions is still ambiguous, which is vital for engineering material design. Therefore, a deep insight into the deformation behavior of AL6XN at elevated temperatures is needed to better understand its application in SCWR.

The structural materials are often subjected to repeated plastic deformation, especially at high temperature. Therefore, fatigue-related mechanical properties at elevated temperatures are necessarily investigated for the optimum engineering design. The study of fatigue has been carried out for nearly 200 years since the middle of the 19th century. A general agreement has been reached that the metal fatigue is actually a problem of microplasticity. The fatigue damage is manifested in the form of irreversible microscopic change on the sample surface, which is resulted from the accumulation 
of small irreversible plastic microstrain [8]. The irreversible dislocation gliding under cyclic loading is accompanied by the straining-localization phenomenon and the formation of slip bands, such as persistent slip bands (PSBs) or persistent Lüders bands (PLBs). PSBs mainly appear in pure face-centered cubic (fcc) metals, such as copper and nickel, in which the cross-slip of dislocation is easy, and thus they are called the wavy slip metals $[9,10]$. The PSBs-related dislocation configuration is a mixture of dipolar walls with high edge dislocation density and channels with low edge/screw dislocations density, which had been well depicted by the composite model [11]. In solid-solution-hardened fcc alloys, such as $\alpha$-brass and certain ASSs, the cross-slip of dislocation is strongly impeded, leading to the formation of planar dislocation arrays (such as PLBs), which are called planar slip alloys [12-14]. Like PSBs, the PLBs-related dislocation configuration is also important for understanding the fatigue damage scenario. In the former researches of fatigue deformation at room temperature of AL6XN ASS [13, 14], PLBs were found to be responsible for undertaking majority of the plastic deformation. By the synchrotron-based X-ray microdiffraction method, the longrange stress field was found to be generated by PLBs and the fatigue damage was mainly dominated by the accumulation of PLBs and the complex interaction among various PLBs. It is well known that except the stacking fault energy (SFE), dynamic strain aging (DSA) and short-range order (SRO), which usually occur during high temperature deformation of ASSs, are all proven to influence deformation mode. The aim of the present work is to investigate fatigue deformation and damage mechanism of AL6XN ASS at elevated temperatures.

\section{Experimental}

The material investigated in this study is AL6XN ASS, a bar with a diameter of $30 \mathrm{~mm}$. The chemical composition (weight percent, wt \%) is presented in Table 1, in which the steel is rich in $\mathrm{Ni}, \mathrm{Cr}$ and $\mathrm{Mo}$, and the content of $\mathrm{Fe}$ is less than $50 \mathrm{wt} \%$. Specimens with the cross section of $3 \mathrm{~mm} \times 4 \mathrm{~mm}$ were prepared for the tensile tests and the loading axis was parallel to the rolling direction $(\mathrm{RD})$ of the bar. The uniaxial tensile tests were carried out at 400,500 and $600{ }^{\circ} \mathrm{C}$, respectively, and the strain rate was $2 \times 10^{-3} \mathrm{~s}^{-1}$. Cylindrical specimens with a gauge length of $30 \mathrm{~mm}$ and a gauge diameter of $6.5 \mathrm{~mm}$ were cut using electric discharge machining and then were mechanically polished using $\mathrm{SiC}$ paper for the fatigue tests. By using a closed-loop servohydraulic fatigue test machine (MTS 809, MTS Systems Corporation, USA), the symmetrical push-pull fatigue tests were carried out on AL6XN ASS in strain-control mode. The strain amplitude was $\pm 0.3 \%$ and the strain rate was $2 \times 10^{-3} \mathrm{~s}^{-1}$, which was controlled by triangular wave form. The fatigue tests were conducted at 400, 500 and $600{ }^{\circ} \mathrm{C}$, respectively. The test temperature was maintained at designated value with an accuracy of $\pm 2{ }^{\circ} \mathrm{C}$ using an infrared furnace (MTS 490-83, MTS Systems Corporation, USA).

The JMS-7001F scanning electron microscope (SEM) equipped with electron backscattering diffraction (EBSD) attachment was used to observe the initial microstructure of AL6XN ASS. The observation plane was electro-polished in a 13 vol. \% perchloric acid and $87 \mathrm{vol} . \%$ ethanol solution. In order to examine the microstructure evolution during deformation, fatigue fracture samples were prepared for transmission electron microscope (TEM) observations by twin-jet electro-polishing in a 5 vol. \% perchloric acid and 95 vol. \% ethanol solution. The JEM-2100F TEM machine was used for microstructure characterization. TEM specimens were cut parallel to the loading direction: thin sheets of $0.5 \mathrm{~mm}$ thick were sectioned by spark-cutting, grounded on both sides before twin-jet electro-polishing. The neutron diffraction and small-angle neutron scattering (SANS) experiments were performed on the high resolution neutron diffractometer (HRND) and Suanni small-angle neutron spectrometer of CMRR (China Mianyang Research Reactor), respectively. The neutron diffraction spectrum was measured in the angular range of $40^{\circ}-127^{\circ}$, and the neutron wavelength is $0.1885 \mathrm{~nm}$. The scattering intensity of SANS was measured as a function of scattering vector, $q=4 \pi \sin \theta / \lambda$, where $\lambda$ is the incident neutron wavelength, and $\theta$ is half of the scattering angle. A mean neutron wavelength of $0.53 \mathrm{~nm}$ with 0.18 full width at half maximum (FWHM) was produced by a multi-blade mechanical velocity selector. Sample-detector distances of 1.8 and $5.3 \mathrm{~m}$ were used to cover a $q$ range of $0.1-2.5 \mathrm{~nm}^{-1}$. The data reduction corrected the raw measured contributions from the air, transmission, and thickness. The absolute intensity was calibrated by a 1-mm-thick water sample, and the scattering data were processed using BerSANS software [15].

\section{Results and Discussion}

\subsection{Cyclic Stress Response}

The initial microstructure of AL6XN ASS is presented in Fig. 1a, which is composed entirely of austenite grains. The majority of the grains are larger than $10 \mu \mathrm{m}$, and a small number of twins appear in the grains. The inverse pole figure
Table 1 Chemical composition (wt $\%$ ) of AL6XN ASS

\begin{tabular}{lllllllll}
\hline $\mathrm{C}$ & $\mathrm{Cr}$ & $\mathrm{Ni}$ & $\mathrm{Si}$ & $\mathrm{Mn}$ & $\mathrm{Mo}$ & $\mathrm{N}$ & $\mathrm{Cu}$ & $\mathrm{Fe}$ \\
\hline 0.016 & 21.6 & 24.0 & 0.36 & 0.23 & 6.1 & 0.21 & 0.10 & Bal. \\
\hline
\end{tabular}


(IPF) of the initial microstructure along the RD, as shown in Fig. 1b, indicates the presence of two weak texture components, i.e., $\{001\} / / \mathrm{RD}$ and $\{011\} / / \mathrm{RD}$. Figure 1c shows the tensile stress-strain curves at 400,500 and $600{ }^{\circ} \mathrm{C}$, respectively. The yield strength and ultimate tensile strength decrease slightly with increasing temperature, especially the yield strength at $600{ }^{\circ} \mathrm{C}$, while the ultimate plastic strain shows a continuous increasing tendency. The serrated flow appeared on the stress-strain curves indicates the occurrence of DSA in the temperature range of $400-600{ }^{\circ} \mathrm{C}$, which is consistent with the results in former literature [7]. The diffusion and segregation of interstitial atoms and substitutional atoms, such as carbon, nitrogen, chromium and molybdenum, are considered to be the mechanism of the serrated flow. The similar yield strengths of the tensile tests at 500 and $600{ }^{\circ} \mathrm{C}$ indicate the strengthening effect of DSA.

The cyclic stress responses for AL6XN ASS as a function of cycles at elevated temperatures are presented in Fig. 2. The initial cyclic stress at different temperatures is higher than the corresponding yield strength in the tensile test (as shown in Fig. 1c), and different cyclic stress responses are observed through the whole fatigue life. In Fig. 2a, fatigue test at $400{ }^{\circ} \mathrm{C}$, the cyclic stress responses can be divided into three stages: A continuous increase in the stress amplitude is observed in the initial cycles, indicating the cyclic hardening behavior appears in the first stage; then, a plateau appears in the second stage, and the cyclic stress shows little variation with the fatigue cycle; finally, in the last stage before fatigue fracture, a second cyclic hardening is observed, as displayed in the magnified rectangular area in Fig. 2a. Compared with the cyclic stress responses at $400{ }^{\circ} \mathrm{C}$, the work hardening behavior disappears on the fatigue curves at 500 and $600{ }^{\circ} \mathrm{C}$. Constant stress keeps through the whole fatigue life until rapid fracture at $500{ }^{\circ} \mathrm{C}$, and continuous cyclic softening appears at $600{ }^{\circ} \mathrm{C}$. Additionally, the initial cyclic stress increases with temperature from 400 to $500{ }^{\circ} \mathrm{C}$, while the retardation in increase of the cyclic stress is noted at $600{ }^{\circ} \mathrm{C}$.

Unlike the 300 series ASSs, AL6XN is highly stable austenite steel due to the high content of nickel and nitrogen elements, implying plasticity-induced martensitic transformation would not occur under this experimental condition. Therefore, cyclic hardening attributed to the plasticity-induced martensitic transformation in 300 series ASSs will not happen in AL6XN ASS. DSA is indeed an a

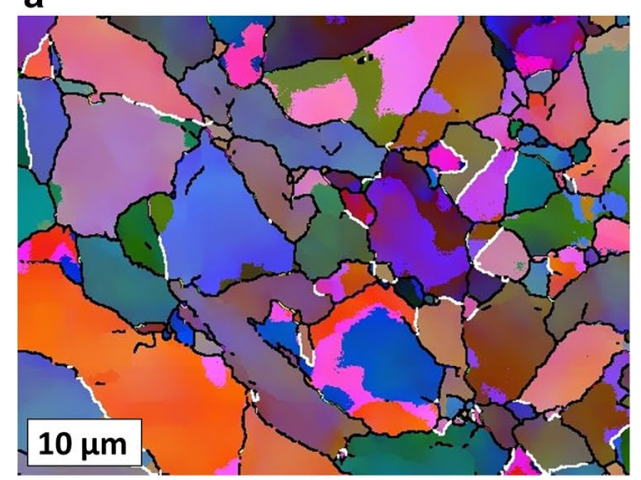

b

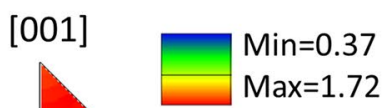

$\operatorname{Max}=1.72$

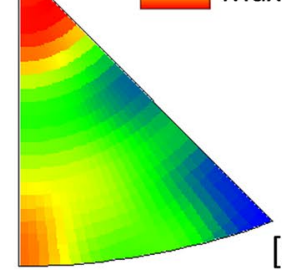

[011]

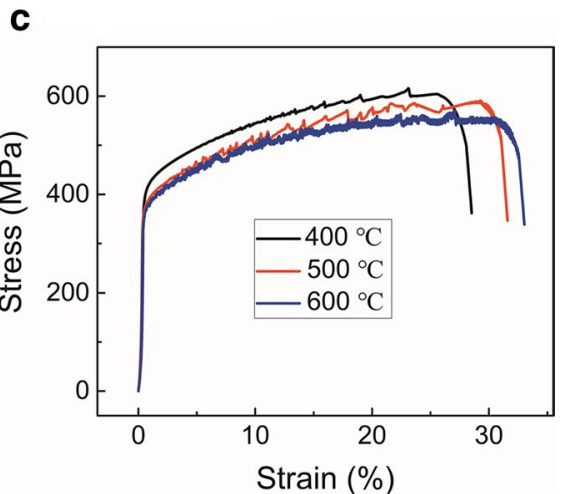

Fig. 1 Initial microstructure a and inverse pole figure (IPF) b of AL6XN ASS (the white lines represent the twins), $\mathbf{c}$ tensile stress-strain curves of AL6XN ASS at elevated temperatures
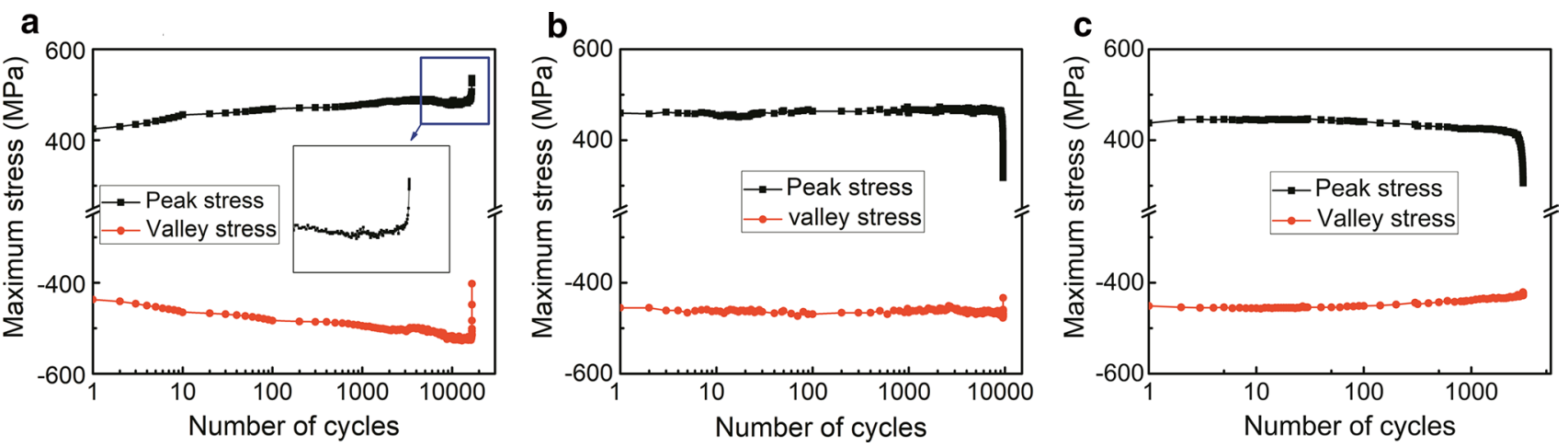

Fig. 2 Cyclic stress responses (on the logarithm scale) for AL6XN stainless steel at $400{ }^{\circ} \mathrm{C} \mathrm{a}, 500{ }^{\circ} \mathrm{C} \mathbf{b}, 600{ }^{\circ} \mathrm{C} \mathbf{c}$ as a function of cycles 
important factor in work hardening, which has been indicated in research $[7,16]$. The solute atoms segregation can effectively impede dislocation glide, resulting in the cyclic hardening behavior on the fatigue curve. In addition, SRO is also a possible phenomenon that occurs during the high temperature deformation of AL6XN ASS, which will make a contribution to the work hardening. It has been indicated in many researches that SRO can contribute to the special mechanical properties of alloys, such as working hardening behavior, planar slip structure of dislocation and serrated flow in stress-strain curve [17-21]. At higher temperatures, cyclic hardening disappears, especially at $600{ }^{\circ} \mathrm{C}$, implying that the dynamic recovery may play an increasingly important role in fatigue deformation. However, more details about the deformation mechanism should to be concluded from further observations of the microstructure.

\subsection{Microstructure Evolution}

\subsubsection{Dislocation Structure}

Figure 3 shows the TEM bright field micrographs of dislocation structures and electron diffraction pattern in [111] zone axis of AL6XN ASS experiencing cyclic loading at $400{ }^{\circ} \mathrm{C}$. The forbidden diffraction spot of $1 / 3\{422\}$ in fcc structure is obviously displayed in Fig. 3c, which is indicative of SRO formed during the fatigue deformation at $400{ }^{\circ} \mathrm{C}$. The same forbidden diffraction spot has been mentioned in many researches [22-26] and the first time that definitive evidence proposed to be caused by SRO is in the research of Alloy 600 by the combination analysis of electron diffraction pattern and neutron diffraction [27]. In Fig. 3a, high-density dislocation tangles are observed, and it is worth to point out that the dislocations configurations are not straight and parallel, but are bowing of dislocations. It is believed that the microstructure is deeply affected by the pinning effect of DSA and SRO, which has already been observed in research [28]. Figure $3 \mathrm{~b}$ shows planar slip bands of dislocation pileup inside the grain. DSA and SRO can promote planar slip and restrict cross-slip of dislocation by the "glide plane softening" phenomenon [29]. The segregation of solute atoms or formation of SRO can effectively impede dislocation glide, causing work hardening. When the external stress is large enough, the clusters will be destroyed by the gliding of the leading dislocation. If there is not enough time for the clusters to recover before the arriving of the next dislocation, gliding in this particular plane becomes easier than in other planes, and the following dislocations will glide in the same way as the leading dislocation, by which planar slip mode is promoted. The straining-localization phenomenon of planar slip band will provide a preferred site for crack initiation and reduce fatigue resistance. During the plastic deformation, the planar slip band becomes the obstacle to a further deformation and restricts the deformation in the band, which results in a severe local deformation.

\subsubsection{Precipitate Phases}

Figure 4 shows the TEM images of the fatigue samples at 500 and $600{ }^{\circ} \mathrm{C}$, three different types of precipitates are formed during the fatigue tests, which are chi $(\chi)$ phase, Laves phase and sigma $(\sigma)$ phase, respectively. Figure $4 \mathrm{a}$, d shows the configuration of $\chi$-phase, i.e., strip and block-type precipitates with the size of $500 \mathrm{~nm}$, which precipitate in grain with high dislocation density and at twin boundary. The $\chi$-phase is crystallized in the cubic system and belongs to the space group "I-43 m" (space group No. 217). The typical composition of $\chi$-phase in ASS is $\mathrm{Fe}_{36} \mathrm{Cr}_{12} \mathrm{Mo}_{10}$, but it is not constant at different conditions [30]. In our research of AL6XN ASS, results obtained by energy dispersive spectroscopy (EDS) attached to SEM show that the primary chemical composition of $\chi$-phase at $500{ }^{\circ} \mathrm{C}$ is about $26.8 \mathrm{wt} \% \mathrm{Cr}, 40.9 \mathrm{wt} \% \mathrm{Fe}, 10.1 \mathrm{wt} \% \mathrm{Ni}$, $22.1 \mathrm{wt} \%$ Mo and $26.4 \mathrm{wt} \% \mathrm{Cr}, 39.9 \mathrm{wt} \% \mathrm{Fe}, 9.9 \mathrm{wt} \% \mathrm{Ni}$, $23.7 \mathrm{wt} \% \mathrm{Mo}$ at $600{ }^{\circ} \mathrm{C}$. In general, the diffusion and segregation of Mo and $\mathrm{Cr}$ in ASS result in the formation of $\chi$-phase during high temperature deformation. The grain boundaries,
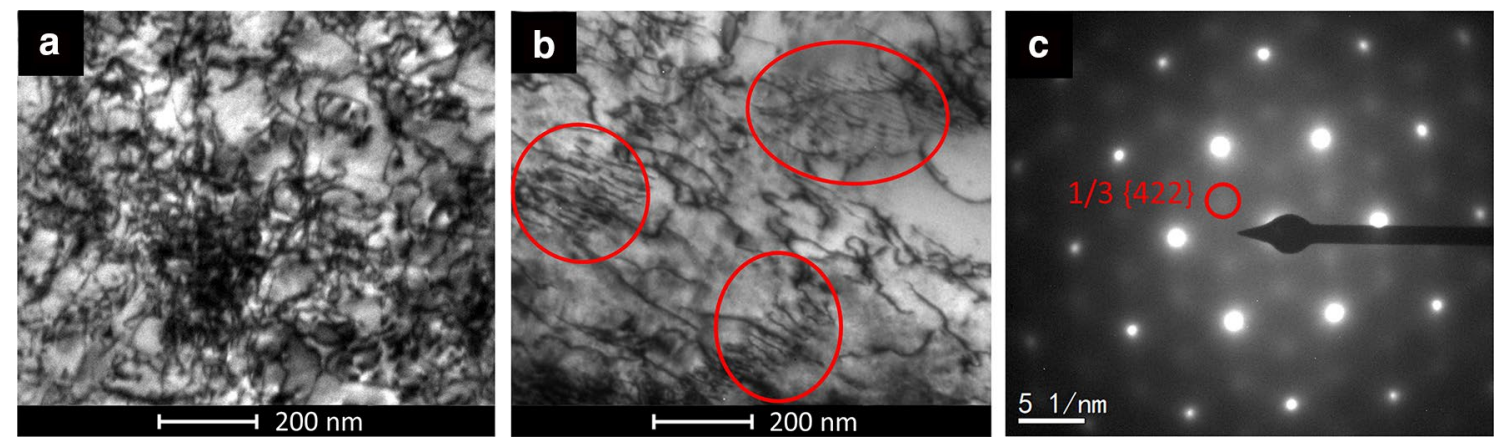

Fig. 3 Dislocation structures and electron diffraction pattern observed in the fatigue sample at $400{ }^{\circ} \mathrm{C}$ : a dislocation tangles, $\mathbf{b}$ planar slip bands, c diffraction pattern in [111] zone axis 

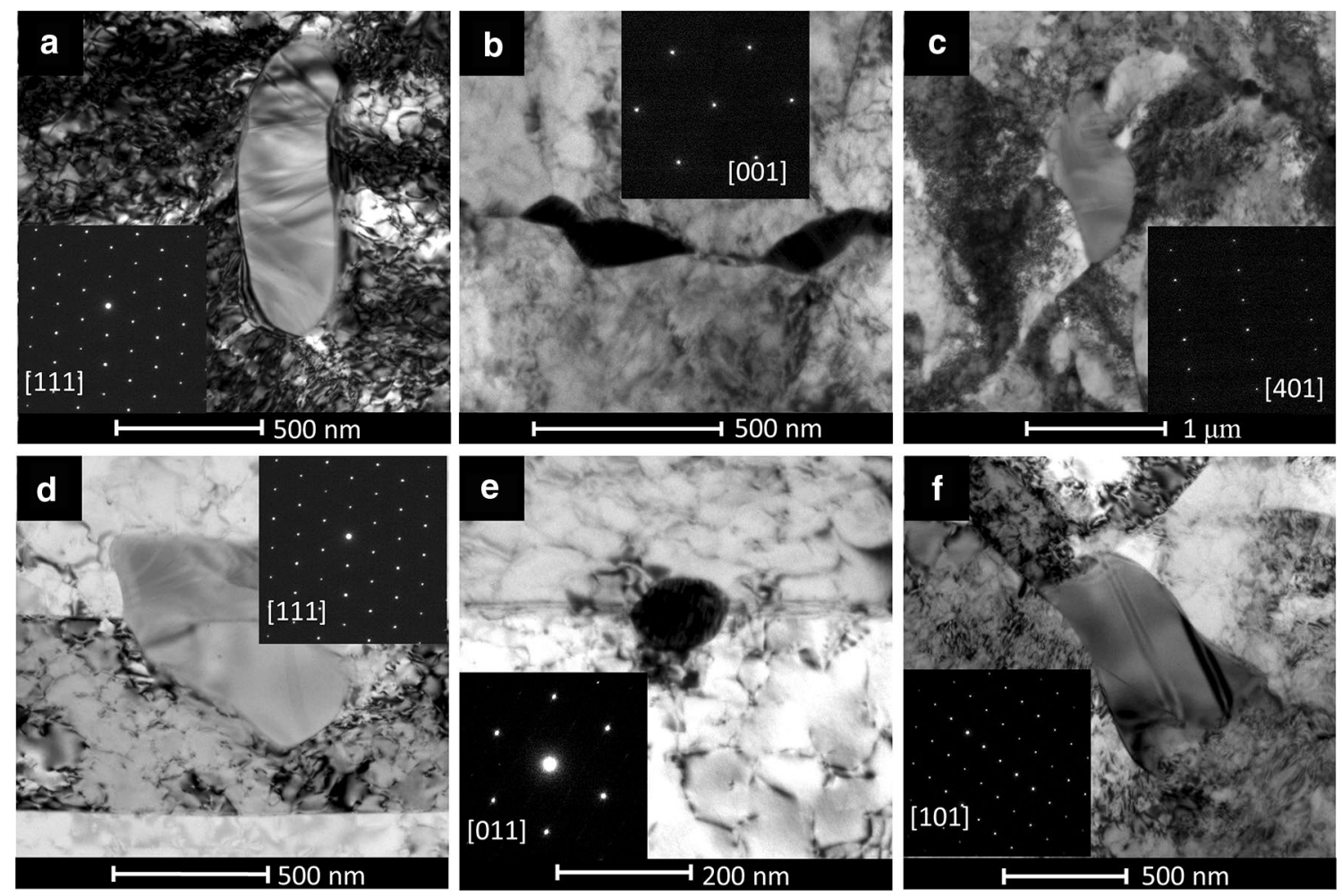

Fig. 4 Microstructures observed in the fatigue samples at $500{ }^{\circ} \mathrm{C} \mathrm{a}-\mathbf{c}, 600{ }^{\circ} \mathrm{C} \mathrm{d}-\mathbf{f}$ : three different types of precipitates

coherent and incoherent twin boundaries, and dislocations within the grains are usually the preferred sites for $\chi$-phase nucleation [31]. The precipitation of $\chi$-phase will lead to local depletion of $\mathrm{Cr}$ element, which not only has a detrimental effect on the corrosion resistance, especially intergranular corrosion resistance, but also leads to embrittlement during thermal deformation. However, the precipitation of $\chi$-phase in AL6XN steel has not been observed yet, relative results have been observed in 316 ASS after higher-temperature aging treatment $[32,33]$. In addition to the $\chi$-phase, the Laves phase is also identified in the fatigue samples. Figure $4 b$, e shows the configuration of Laves phases nucleated at grain boundary and twin boundary. The size of the Laves phases is about $200 \mathrm{~nm}$, which is smaller than the $\chi$-phase. The Laves phase is indexed to a hexagonal close-packed structure with the zone axes of [001] and [011] observed in Fig. 4b, e. The Laves phase is rich in Mo, as measured via EDS: the primary chemical composition precipitated in the AL6XN steel at $500{ }^{\circ} \mathrm{C}$ is about $16.2 \mathrm{wt} \% \mathrm{Cr}, 31.1 \mathrm{wt} \% \mathrm{Fe}, 8.9 \mathrm{wt} \% \mathrm{Ni}, 43.7 \mathrm{wt} \% \mathrm{Mo}$ and $16.8 \mathrm{wt} \% \mathrm{Cr}, 29.8 \mathrm{wt} \% \mathrm{Fe}, 8.5 \mathrm{wt} \% \mathrm{Ni}, 44.8 \mathrm{wt} \% \mathrm{Mo}$ at $600{ }^{\circ} \mathrm{C}$. The morphology of Laves phase varies from plate-like to globular-like. The plate-like and needle-like precipitates are usually the sites where dislocations pileup preferentially, causing detrimental effects. Figure $4 \mathrm{c}$ and $\mathrm{f}$ shows that the sigma phase also precipitates in AL6XN ASS. The sigma phase is crystallized in the monoclinic system and belongs to the space group 'P121' (space group No. 3). The particle size is about $500 \mathrm{~nm}$, which is similar to that of $\chi$-phase. The sigma phase prefers to nucleate at the grain boundaries, in which stack fault is observed. EDS results show that the primary chemical composition of sigma phase precipitated in the AL6XN steel at $500{ }^{\circ} \mathrm{C}$ is about $30.9 \mathrm{wt} \% \mathrm{Cr}, 38.9 \mathrm{wt} \% \mathrm{Fe}, 11.2 \mathrm{wt} \%$ $\mathrm{Ni}, 19 \mathrm{wt} \%$ Mo and $30.7 \mathrm{wt} \% \mathrm{Cr}, 39.4 \mathrm{wt} \% \mathrm{Fe}, 11 \mathrm{wt} \% \mathrm{Ni}$, $18.7 \mathrm{wt} \%$ Mo at $600{ }^{\circ} \mathrm{C}$. The sigma phase is a common precipitate in high temperature deformation of ASS. When the contents of forming elements $\mathrm{Cr}$ and Mo are sufficiently high, it is possible for the sigma phase to precipitate [34].

Figure 5a shows SANS results of the scattering intensity versus the scattering vector $q$ of the AL6XN ASS. Firstly, in high $q$ range, there is no significant variation in the scattering intensity with increasing fatigue temperatures, which indicates no variation of small clusters at higher temperatures. However, in the low $q$ range, the scattering intensity increases obviously with the fatigue temperatures. In logarithmic coordinate, all the scattering curves obey Porod law, which is expressed as:

$I(q)=\frac{2 \pi(\Delta \rho)^{2} S_{\mathrm{v}}}{q^{4}}+C$,

where $\Delta \rho$ is the difference in scattering length densities between the precipitates and the matrix, $S_{\mathrm{V}}$ is the total interfacial surface area per unit volume, and $C$ is the constant of 

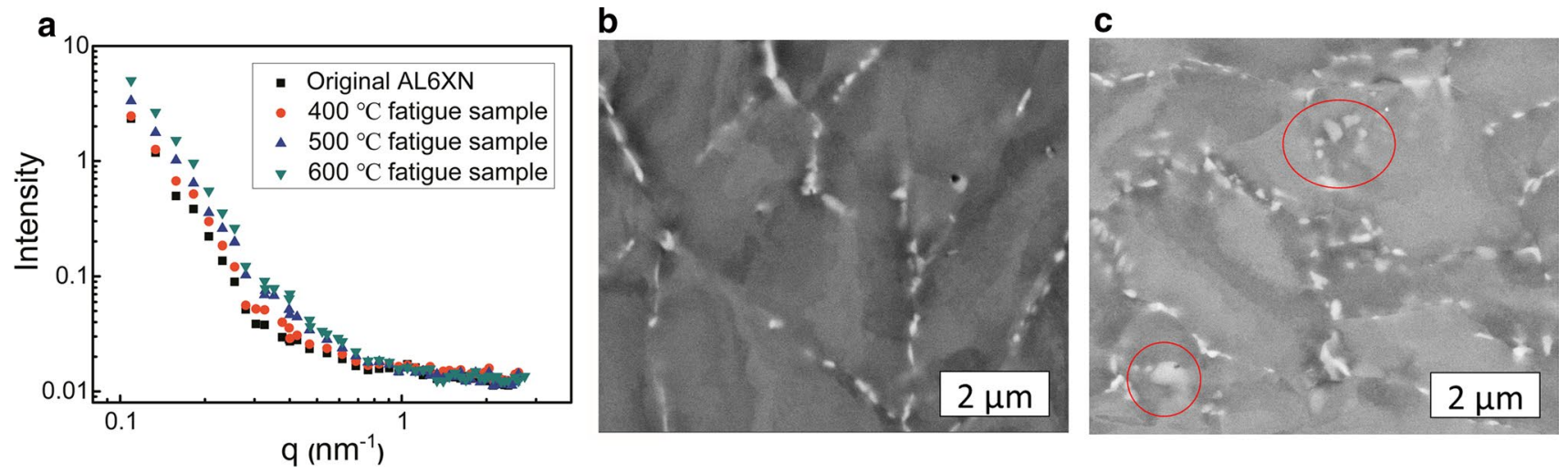

Fig. 5 a SANS results of AL6XN ASS: the scattering intensity versus the scattering vector q, b, $\mathbf{c}$ SEM micrographs of precipitates in fatigue samples at 500 and $600{ }^{\circ} \mathrm{C}$, respectively

background. Such behaviors of SANS curves indicate the presence of a wide distribution of scattering inhomogeneity with the size larger than $30 \mathrm{~nm}$ (estimated by $\pi / q_{\min }$ ), which is consistent with the result in TEM. However, due to the limited $q$ range, the size distribution cannot be derived from the SANS results. The amount of the precipitates is approximately reflected in the parameter of $S_{\mathrm{V}}$, as listed in Table 2 . Compared with the original sample, $S_{\mathrm{V}}$ of the sample treated at $600{ }^{\circ} \mathrm{C}$ increases by nearly 2 times, indicating that the volume fraction of the precipitates increases with the fatigue temperature. Figure $5 b, c$ shows the distribution of precipitates in the fatigue samples at 500 and $600{ }^{\circ} \mathrm{C}$, respectively. Backscattered electron of SEM, which reflects the distribution of chemical components, was used for the image. As shown in Fig. 5b, c, the precipitates in fatigue sample at 500 ${ }^{\circ} \mathrm{C}$ mainly distribute along the grain boundaries, and the size is relatively uniform. When fatigue temperature increases to $600{ }^{\circ} \mathrm{C}$, the number of precipitates in the grain interiors increases, and the size of some precipitates becomes larger, as marked in the red circles in Fig. 5c.

\subsection{Deformation Mechanism}

Figure 6a shows the TEM bright field micrographs of the original AL6XN ASS. Extensive dislocation network distributed in the interior of grains can be evidenced, indicating multiple slip systems have been activated and a highdensity of dislocations already exist in the original sample. Figure $6 \mathrm{~b}, \mathrm{c}$ shows the TEM bright field micrographs of the fatigue samples at 500 and $600{ }^{\circ} \mathrm{C}$. Affected by the initial microstructure, dislocation tangle is an important deformation structure in the fatigue tests at $400-600{ }^{\circ} \mathrm{C}$, as shown in
Figs. $3 a$ and $6 \mathrm{~b}$. In addition, affected by DSA and SRO, planar slip mode is facilitated in the fatigue tests, as shown in Figs. $3 b$ and $6 c$. Planar configuration of large groups forming extended pileup and multipole structures is the second deformation structure in the fatigue tests at $400-600{ }^{\circ} \mathrm{C}$. Planar slip bands play an important role in fatigue deformation and fracture at $400{ }^{\circ} \mathrm{C}$. However, the most important factor in fatigue damage at 500 and $600{ }^{\circ} \mathrm{C}$ is believed to be originated from the precipitates. Three kinds of precipitates were observed in the fatigue samples at 500 and $600{ }^{\circ} \mathrm{C}$. A temperature range which is not common for those phases to form in AL6XN austenitic stainless steel [5], indicating the initial microstructure, with a relatively large amount of dislocations, may play an important role in precipitation process. The lattice distortion area of dislocation provides a much convenient channel for the diffusion of substitutional atoms of $\mathrm{Cr}$ and $\mathrm{Mo}$ in slip bands or to grain boundaries, which accelerates the phase transformation from austenitic matrix to chi phase, Laves phase and $\sigma$-phase. Three kinds of precipitates all have topologically close-packed structures, which belong to brittle phases even at high temperature [35]. Moreover, in our study, the distribution of precipitates in fatigue samples is inhomogeneous, and some of the particles are relatively large in size, especially at $600{ }^{\circ} \mathrm{C}$. During the plastic deformation, on the one hand, the brittle phases cannot deform coordinately with the austenitic matrix, and thus a large number of dislocations will be piled up at the interface of the precipitates; on the other hand, the interfaces between precipitates and austenitic phase are inherently weakly bonded. When the local strain reaches a certain degree, crack will be generated. The precipitates play a predominant role in the rapid decrease in fatigue life at
Table $2 S_{\mathrm{V}}$ obtained from Porod fitting

\begin{tabular}{lllll}
\hline & Original sample & $400{ }^{\circ} \mathrm{C}$ fatigue sample & $500{ }^{\circ} \mathrm{C}$ fatigue sample & $600{ }^{\circ} \mathrm{C}$ fatigue sample \\
\hline$S_{\mathrm{V}}$ & $0.0024 \pm 7.7 \mathrm{E}-5$ & $0.0025 \pm 1.3 \mathrm{E}-4$ & $0.0036 \pm 1.3 \mathrm{E}-4$ & $0.0070 \pm 1.7 \mathrm{E}-4$ \\
\hline
\end{tabular}



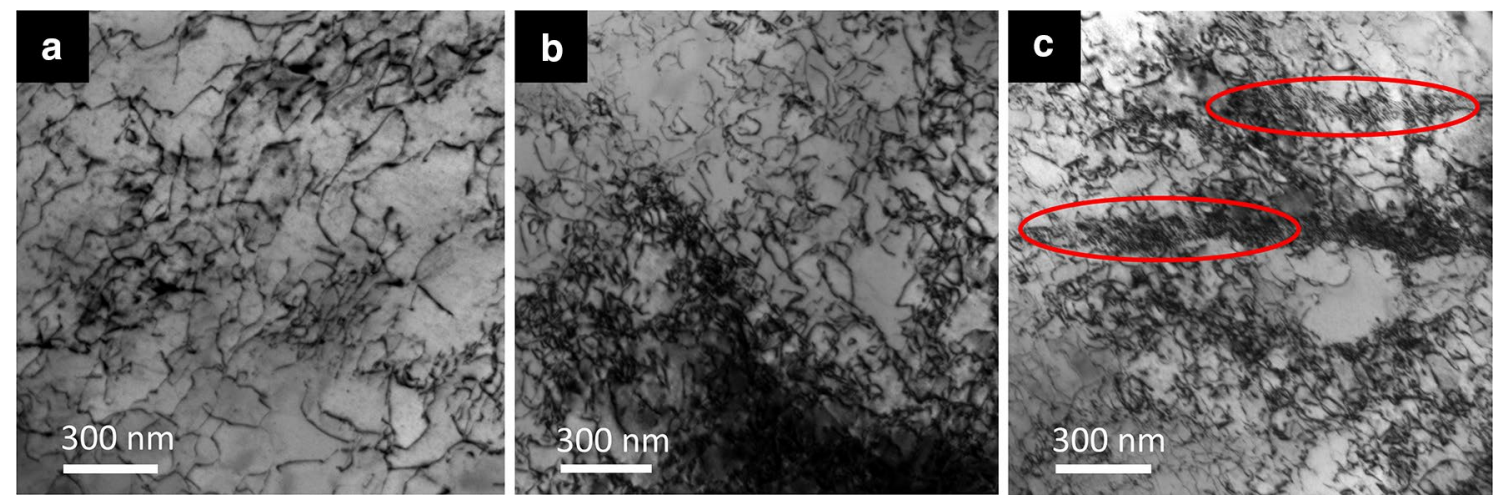

Fig. 6 TEM bright field micrographs of the original AL6XN ASS a, and the fatigue samples of AL6XN ASS at $500{ }^{\circ} \mathrm{C} \mathbf{b}, 600{ }^{\circ} \mathrm{C} \mathrm{c}$

elevated temperature. Figure 7 a shows the precipitates at grain boundary, and an obvious crack originated from the grain boundary.

Cyclic hardening is the most obvious feature of the fatigue curve at $400{ }^{\circ} \mathrm{C}$, which is believed to be caused by DSA and SRO. As shown in Fig. 2a, for the first stage of cyclic hardening, in addition to the contribution of dislocation density, SRO and DSA also play a non-negligible role. DSA and SRO increase extra stress which is needed for a dislocation to get through the segregation of solute atoms. Under the effect of "glide plane softening" phenomenon of DSA and SRO, the dislocation structure of planar slip bands gradually develops in some grains, which brings a lowered stress response. Thus, stress saturation appears on the fatigue curve. Finally, a second cyclic hardening appears on the fatigue curve, which is considered to be deeply related with DSA and SRO. A large number of slip bands have been formed during the stress saturation stage. It is generally believed that dynamic recovery is suppressed by planar slip. The formation of a large number of solute atoms clusters and SRO in the slip bands brings a great resistance to the movement of dislocations, which results in the second work hardening on the fatigue curve.

Continuous cyclic softening behavior is observed in Fig. $2 \mathrm{c}$ on the fatigue curve at $600{ }^{\circ} \mathrm{C}$, indicating that dynamic recovery plays an increasingly important role in fatigue deformation [36]. Figure $7 \mathrm{~b}$ shows the TEM bright field micrograph of the fatigue sample at $600{ }^{\circ} \mathrm{C}$. In addition to the planar slip bands and dislocation tangles, dynamic recovery regions inside the grain with low dislocation density, as marked by the red circles, are also observed. Dynamic recovery is the process of dislocations elimination and rearrangement, which is accompanied by the decrease in dislocation density and may be reflected in the FWHM of neutron diffraction peak. Thus, representative neutron diffraction profiles of AL6XN ASS experiencing fatigue deformation at 400,500 and $600{ }^{\circ} \mathrm{C}$ were measured. Four diffraction peaks at $2 \theta$ values of $53.7^{\circ}, 62.9^{\circ}, 95.3^{\circ}$ and $120.1^{\circ}$, respectively, are displayed in Fig. 8a. Obviously, except for four peaks undoubtedly belonging to the austenitic matrix of the AL6XN steel, no other distinguishable peaks are observed, indicating the content of the precipitates is
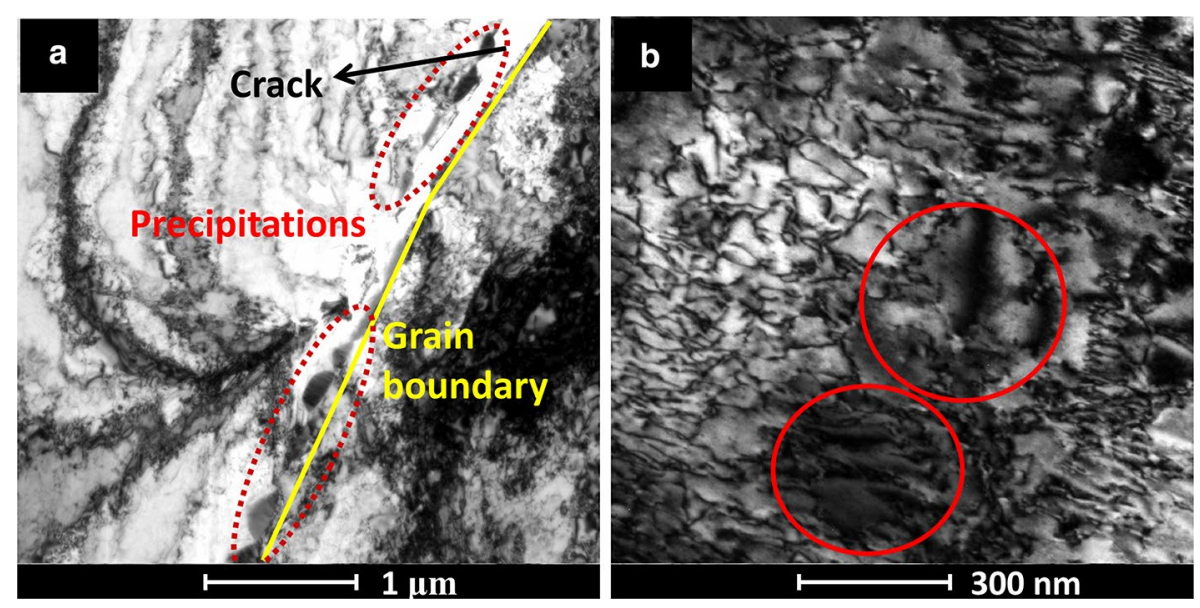

Fig. 7 Micro-crack originated from grain boundary a, micrograph of dislocation structures $\mathbf{b}$ in the fatigue sample at $600{ }^{\circ} \mathrm{C}$ 
too small to be detected in this neutron diffraction pattern. Figure $8 \mathrm{~b}$ shows the peak width analysis of the conventional Williamson-Hall plots at elevated fatigue temperature. The conventional Williamson-Hall method is a mathematical model of the peak width proposed by Williamson and Hall to show the effects of grain size and lattice distortion on FWHM of diffraction peaks. The model can be expressed as a mathematical transformation [37]:

$\Delta K=0.9 / d+\Delta K^{\mathrm{D}}$,

where $d$ is the average grain size, $\Delta K=2 \cos \theta(\Delta \theta) / \lambda, \theta$ and $\lambda$ are the diffraction angle and wavelength of the neutron beam, respectively, $\Delta \theta$ is the FWHM, $\Delta K^{\mathrm{D}}$ is the strain contribution to the line broadening, and $K=2 \sin \theta / \lambda$.

In the conventional Williamson-Hall plot, $\Delta K$ is assumed to be a linear or a quadratic function of $K$. The linear fit of the three samples in Fig. 8b shows that the slope increases with fatigue temperature. According to the conventional Williamson-Hall theory, the slope of the linear fit reflects the lattice distortion: the larger the slope of the line, the more the lattice distortion. Therefore, the results in Fig. 8b indicate that the lattice distortion increases with the fatigue temperatures. However, if the lattice distortion is completely caused by dislocations, it is in contradiction with our expectation that dynamic recovery should play a more important role with the increase in fatigue temperature [36]. Figure 8c shows the micrograph of Laves phase at grain boundary, where the EDS results of the Mo content of the three points $\mathrm{A}, \mathrm{B}$ and $\mathrm{C}$, as marked in red circles, are $37.53 \mathrm{wt} \%$, $4.56 \mathrm{wt} \%$, and $6.03 \mathrm{wt} \%$, respectively. The formation of the Laves phase causes the Mo-depleted area around the grain boundary, indicating precipitate would induce non-uniform distribution of chemical composition in fatigue samples at 500 and $600{ }^{\circ} \mathrm{C}$. The fluctuation in the local chemical composition results in the fluctuation of lattice constant, which will contribute to the lattice distortion and result in the broadening of FWHM. Thus, it can be concluded that, in addition to dislocation density, the non-uniform distribution of chemical composition caused by precipitation or segregation of solute atoms is another factor contributing to the broadening of FWHM, and dynamic recovery causes the cyclic softening on the fatigue curve at $600{ }^{\circ} \mathrm{C}$.

\section{Conclusions}

The low-cycle fatigue tests have been conducted in the temperature range of $400-600{ }^{\circ} \mathrm{C}$ for AL6XN ASS and the following conclusions are drawn:

(1) DSA and SRO occur in the fatigue test at $400{ }^{\circ} \mathrm{C}$, which play an important role in the cyclic hardening behavior on the fatigue curve. Additionally, under the effect of glide plane softening phenomenon of DSA and SRO, planar slip of dislocation is facilitated during the fatigue deformation. The microstructure results indicate the fatigue damage is mainly dominated by the accumulation of planar slip band and the interaction among various slip systems.

(2) Three types of precipitates: chi phase, Laves phase and sigma phase, were formed in the fatigue tests at 500 and $600{ }^{\circ} \mathrm{C}$. An increase in precipitation content with temperature has been confirmed by SEM and SANS analysis. The dislocation pileup originated from the uncoordinated deformation between precipitate and austenitic matrix is an important fatigue damage leading to crack initiation.

(3) The continuous cyclic softening behavior was also observed on the fatigue curve at $600{ }^{\circ} \mathrm{C}$, indicating that dynamic recovery plays an increasingly important role in fatigue deformation. However, linear analysis of neutron diffraction peak shows that the lattice distortion increases with the fatigue temperatures. Further a

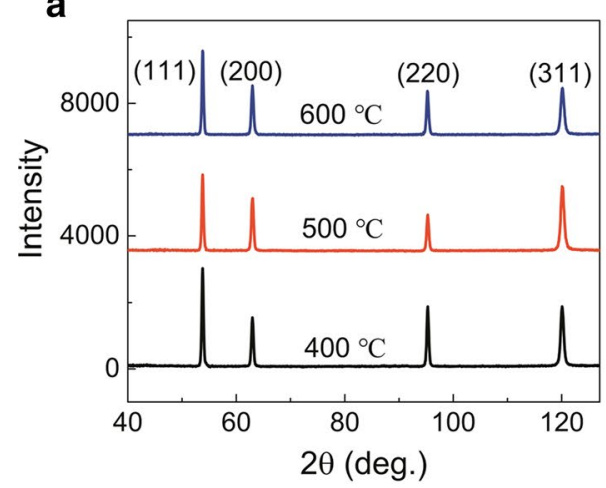

b

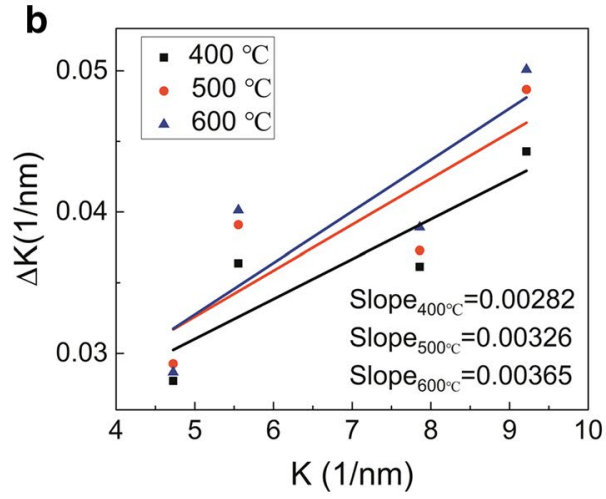

C

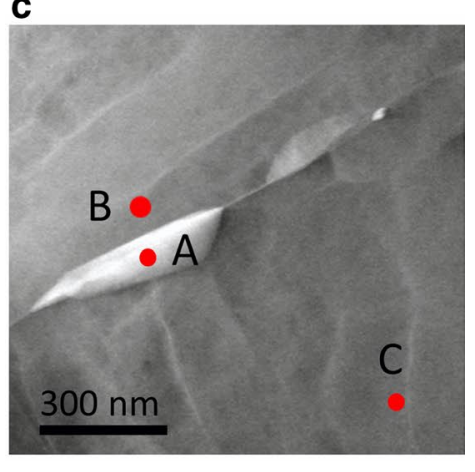

Fig. 8 Neutron diffraction patterns $\mathbf{a}$, conventional Williamson-Hall plots $\mathbf{b}$, of the fatigue samples at elevated temperatures, $\mathbf{c}$ micrograph of Laves phase in fatigue sample at $600{ }^{\circ} \mathrm{C}$ 
analysis indicates that the segregation of solute atoms and formation of precipitates lead to fluctuations in the local chemical composition which makes a nonnegligible contribution to lattice distortion.

Acknowledgements This work was supported by the National Natural Science Foundation of China (No. 51231002).

\section{References}

[1] K.L. Murty, I. Charit, J. Nucl. Mater. 383, 189 (2008)

[2] J.Q. Zhang, R. Hu, J. Wang, J.S. Li, Acta Metall. Sin. Engl. Lett. 27, 1046 (2014)

[3] E.E. Denhard, R.H. Espy, Met. Eng. Quart. 12, 18 (1972)

[4] J.A. Brooks, J.C. Lippold, ASM Handbook 6, 457 (1990)

[5] L.J. Meng, J. Sun, H. Xing, W.W. Yu, F. Xue, Nucl. Eng. Des. 241, 2839 (2011)

[6] S. Kalnaus, F. Fan, A.K. Vasudevan, Y. Jiang, Eng. Fract. Mech. 75, 2002 (2008)

[7] L.J. Meng, J. Sun, H. Xing, G.W. Pang, J. Nucl. Mater. 394, 34 (2009)

[8] H. Mughrabi, Metall. Mater. Trans. A 40, 1257 (2009)

[9] C. Laird, in Dislocations in Solids, ed. by F.R.N. Nabarro (NorthHolland Publishing Company, New York, 1983), p. 57

[10] C.E. Feltner, C. Laird, Acta Metall. 15, 1621 (1965)

[11] H. Mughrabi, Metall. Mater. Trans. B Process Metall. Mater. Process. Sci. 40, 431 (2009)

[12] P. Lukáš, M. Klesnil, in Corrosion Fatigue, ed. by O.J. Devereux, A.J. McEvily, R.W. Staehle (NACE-2, Houston, 1972), p. 118

[13] R.G. Li, Q.G. Xie, Y.D. Wang, W.J. Liu, M.G. Wang, G.L. Wu, X.W. Li, M.H. Zhang, Z.P. Lu, C. Geng, T. Zhu, Proc. Natl. Acad. Sci. U. S. A. 115, 483 (2018)

[14] R.G. Li, Y.D. Wang, W.J. Liu, C. Geng, Q.G. Xie, D.E. Brown, K. An, Acta Mater. 165, 336 (2019)
[15] U. Keiderling, Appl. Phys. A 74, 1455 (2002)

[16] J. Tian, Y. Yang, L.P. Zhang, X.J. Shao, J. Du, Q.H. Kan, Acta Metall. Sin. Engl. Lett. 30, 822 (2017)

[17] S. Heino, B. Karlsson, Acta Mater. 49, 353 (2001)

[18] M. Grujicic, W.S. Owen, Acta Metall. Mater. 43, 4201 (1995)

[19] R. Taillard, J. Foct, in Proceedings of High Nitrogen Steels, HNS 88, ed. by J. Foct, A. Hendry (The Institute of Metals, Lille, 1988), p. 387

[20] L. Chen, H.S. Kim, S.K. Kim, B.C. De Cooman, ISIJ Int. 47, 1804 (2007)

[21] P.T. Hua, W.H. Zhang, L.J. Huang, W.R. Sun, Acta Metall. Sin. Engl. Lett. 30, 869 (2017)

[22] K. Sato, M. Ichinose, Y. Hirotsu, Y. Inoue, ISIJ Int. 52, 868 (2007)

[23] D.P. Abraham, C.J. Altstetter, Metall. Mater. Trans. A 26, 2859 (1995)

[24] L. Luo, W. Jie, Y. Xu, Y. He, L. Xu, L. Fu, R. Soc, Chem. 16, 5073 (2014)

[25] X.J. Jiang, J. Tafto, B. Noble, B. Holme, G. Waterloo, Metall. Mater. Trans. A 31, 339 (2000)

[26] A. Marucco, B. Nath, J. Mater. Sci. 23, 2107 (1988)

[27] Y.S. Kim, Y.M. Wan, S.S. Kim, Acta Mater. 83, 507 (2015)

[28] P. Verma, G. Sudhakar Rao, P. Chellapandi, G.S. Mahobia, K. Chattopadhyay, N.C. Santhi Srinivas, V. Singh, Mater. Sci. Eng. A 621, 39 (2015)

[29] V. Gerold, H.P. Karnthaler, Acta Metall. 37, 2177 (1988)

[30] J. Anburaj, S.S. Mohamed Nazirudeen, R. Narayanan, B. Anandavel, A. Chandrasekar, Mater. Sci. Eng. A 535, 99 (2012)

[31] A.F. Padilha, P.R. Rios, ISIJ Int. 42, 325 (2002)

[32] Y. Minami, H. Kimura, Y. Ihara, Mater. Sci. Technol. 2, 795 (1986)

[33] J.K.L. Lai, Mater. Sci. Eng. A 58, 195 (1983)

[34] M. Breda, M. Pellizzari, M. Frigo, Acta Metall. Sin. Engl. Lett. 28, 331 (2015)

[35] L.J. Meng, J. Sun, H. Xing, J. Nucl. Mater. 427, 116 (2012)

[36] Y.Y. Hong, S.L. Li, H.J. Li, J. Li, G.A. Sun, Y.D. Wang, Metall. Mater. Trans. A 49, 3237 (2018)

[37] G.K. Williamson, W.H. Hall, Acta Metall. 1, 22 (1953) 